\title{
Pemanfaatan Sampah Plastik untuk Dijadikan Barang Bernilai Ekonomis di Desa Ganti Kecamatan Praya Timur
}

\author{
Jono Iskandar, Armansyah \\ Akom Sumbawa. Jl. Raya Olat Maras Desa Pernek, Kec. Moyo Hulu Kabupaten Sumbawa \\ Besar, Indonesia \\ *Corresponding author email: jiiskandar89@gmail.com
}

\section{Diterima: Agustus 2019; Revisi: Oktober 2019; Diterbitkan: November 2019}

\begin{abstract}
Abstrak
Pencemaran lingkungan disebabkan oleh banyaknya tumpukan sampah yang sangat mengganggu di lingkungan. Pemanfaatan sampah pelastik menjadi hiasan dan atau bahan alternatif pengisian bantal merupakan salah satu bentuk kegiatan mengurangi penumpukan sampah pelastik. Oleh karena itu, penting dilakukan pelatihan dan pembimbingan tata cara pemanfaatan sampah pelastik menjadi barang-barang bernilai ekonomis. Kegiatan ini melibatkan ibu-ibu rumah tangga di Desa Ganti Kecamatan Praya Timur Lombok Tengah NTB. Kegitan tersebut berjalan sesuai tahapan yang direncanakan sebagai berikut: a) memberikan penjelasan umum tentang materi pemanfaatan sampah, b) pengadaan alat dan bahan, c) pembuatan barang-barang bernilai ekonomis. Hasil dari kegitan antara lain 1) adanya peningkatan pengetahuan mitra dalam pengolahan sampah plastik menjadi produk yang memeiliki nilai guna dan ekonimis, 2) terbentuknya keterampilan mitra dalam pengolahan sampah plastik menjadi beberapa produk, seperti sarung bantal, bunga dan beberapa barang yang bernilai ekonomis, dan 3) terbentuknya kesadaran mitra bahwa sampah platik merupakan masalah yang harus diatasai baik dengan cara meminimalisir penggunaan dan pengolahan.
\end{abstract}

Kata Kunci: Sampah Plastik; Barang Bernilai Ekonomis

\section{Utilization of Plastic Waste to Become Economical Value Goods in the Village of Change, Praya Timur District}

\begin{abstract}
Environmental pollution is caused by a large pile of garbage which is very disturbing in the environment. The use of plastic waste for decoration and / or alternative materials for filling pillows is one form of activity to reduce plastic waste buildup. Therefore, it is important to carry out training and guidance on how to use plastic waste into items of economic value. This activity involved housewives in the village of Ganti Praya Timur, Central Lombok, NTB. These activities run according to the planned stages as follows: a) provide a general explanation of waste utilization materials, b) procurement of tools and materials, c) manufacture of goods of economic value. The results of these activities include 1) an increase in partners 'knowledge in processing plastic waste into products that have use and economic value, 2) the formation of partners' skills in processing plastic waste into several products, such as pillowcases, flowers and several items of economic value, and 3) the formation of partner awareness that plastic waste is a problem that must be addressed properly by minimizing its use and processing.
\end{abstract}

Keywords: Plastic Waste; Economical Value Goods

How to Cite: Iskandar, J., \& Armansyah, A. (2019). Pemanfaatan Sampah Plastik untuk Dijadikan Barang Bernilai Ekonomis di Desa Ganti Kecamatan Praya Timur. Lumbung Inovasi: Jurnal Pengabdian kepada Masyarakat, 4(2), 56-60. doi:https://doi.org/10.36312/linov.v4i2.455

https://doi.org/10.36312/linov.v4i2.455

Copyright@ 2019, Iskandar \& Armansyah This is an open-access article under the CC-BY License. (c) (i)

\section{PENDAHULUAN}

Peningkatan kuantitas sampah merupakan konsekuensi logis dari perkembangan dan pertumbuhan penduduk. Peningkatan penggunaan plastik untuk keperluan rumah tangga berdampak pada peningkatan timbunan sampah plastik. Indonesia menjadi nomor 
dua penyumbang sampah plastik dunia yang mengotori seluruh samudra. Setiap tahunya indonesia menyumbang sekitar 1.29 juta metric ton. Padahal pada kenyataanya sampah botol plastik baru akan terurai sekitar 450 tahun. Bisa dibayangkan berapa sampah plastik yang akan bertambah setiap tahunya jika tidak dilakukan pencegahan dini. Sampah plastik yang tidak terpungut oleh pemulung, penanganannya tidak bisa dilakukan dengan metode landfill atau open dump. Pemusnahan sampah plastik dengan cara pembakaran (incineration), kurang efektif dan beresiko sebab dengan pembakaran munculnya polutan dari emisi gas buang (CO2, $\mathrm{CO}$, NOx, dan $\mathrm{SOx}$ ) dan beberapa partikulat pencemar lainnya sehingga diperlukan cara pengolahan lain untuk mengolah sampah plastik (Wicaksono, \& Arijanto, 2017).

Di desa maupun di kota persoalan sampah menjadi persoalan utama yang mempengaruhi kondisi lingkungan. Hal ini disebabkan karena berbagai faktor seperti gaya hidup, perilaku konsumtif dan hidup yang mengandalkan pada makanan siap saji. Rizal (2011) masyarakat yang tidak mengindahkan masalah sampah yang sebenarnya mereka adalah sumber terbesar sebagai penghasil sampah. Undang-Undang Republik Indonesia Nomor 18 Tahun 2008, menetapkan sampah sebagai sisa kegiatan sehari-hari manusia dan/atau proses alam yang berbentuk padat. Sampah dapat dibedakan menjadi 3 (tiga) jenis yaitu: (a). Sampah rumah tangga, (b). Sampah sejenis sampah rumah tangga, dan (c). Sampah spesifik. Sampah yang dihasilkan oleh aktivitas manusia dapat digolongkan berdasarkan beberapa kriteria yang meliputi asal, komposisi, bentuk, lokasi, proses terjadinya, sifat dan jenis (UU Pengolahan Sampah, 2008).

Sampah merupakan masalah lingkungan hidup yang harus ditangani serius karena dapat mengakibatkan kerusakan dan pencemaran lingkungan serta secara tidak langsung dapat memperparah efek pemanasan global. Misalnya saja sampah plastik setiap tahun telah membunuh hingga 1 (satu) juta burung laut, 100.000 mamalia laut dan ikan-ikan yang tidak terhitung jumlahnya (Dani, 2018). Dari data Kementrian Lingkungan Hidup (KLH) Tahun 2017 dalam Baqiroh (2019) menunjukkan, volume timbunan sampah di 194 kabupaten dan kota di Indonesia mencapai 666 juta liter atau setara 42 juta kilogram, dimana komposisi sampah plastik mencapai 14 persen atau enam juta ton. Tahun 2017, menurut KLH jumlah sampah meningkat hingga mencapai 64 juta ton, 11 persen di antaranya merupakan sampah plastik. Termasuk di desa Ganti Kecamatan Praya Timur jumlah sampah terus meningkat setiap tahun. Data tersebut meningkat seiring dengan bertambahnya jumlah penduduk, dengan kata lain jumlah sampah berbanding lurus dengan jumlah penduduk. Kesimpulan dari data tersebut adalah semakin banyak penduduk, semakin banyak sampah sehingga lingkungan hidup pun menjadi kumuh dan tidak sehat. Lazimnya sampah dikurangi dengan cara membakar atau ditimbun, namun dampak pembakaran yang kurang sempurna mengakibatkan polusi udara dalam bentuk dioksin yang dapat menimbulkan berbagai penyakit.

Dalam pengabdian kepada masyarakat ini, berupaya untuk berinovasi kreatif dalam memanfaatkan sampah sehingga menjadi barang terpakai dan bernilai ekonomis. Jenis sampah yang akan dibudidaya adalah plastik. Masyarakat dapat berkreasi dan membantu dalam upaya pengurangan jumlah sampah di lingkungan dengan memanfaatkan sampahsampah tersebut menjadi barang bernilai atau barang alternatif kebutuhan rumah tangga, seperti bantal, pot bunga, manik-manik, tas dan hiasan dinding. Sampah plastik dapat dimanfaatkan dengan cara pemakaian kembali (reuse) maupun daur ulang (recycle). Pada umumnya pemanfaatan sampah plastik digunakan dalam skala rumah tangga yaitu dengan pemakaian kembali pada keperluan yang berbeda, misalnya tempat cat yang terbuat dari plastik digunakan untuk ember atau pot bunga. Sedangkan, pemanfaatan sampah plastik dengan cara daur ulang umumnya dilakukan oleh industri pengelohan produk dengan bahan baku plastik.

Fokusnya pengabdian ini adalah memanfaatkan sampah plastik sebagai isi bantal atau pengganti busa dan sejenisnya. Bantal yang berkualitas adalah bantal yang berdaya tahan lama dengan waktu yang bertahun-tahun. Tidak hanya itu, ia punya keindahan yang memiliki nilai estetika. Handoyo (2019) produk yang berkualitas adalah produk yang keseluruhan ciri dan karateristiknya memberikan kepuasan bagi konsumen serta dapat memenuhi kebutuhannya. Salah satu cara untuk meningkatkan kepuasan bagi konsumen yaitu dengan cara membuat produk yang unik dan memiliki keindahan atau bernilai estetika (Buntojo, 2019). 
Bila produk tersebut diproduksi sebanyak-banyaknya dan dipasarkan maka akan berdampak pada peningkatan nilai ekonomis masyarakat (Mawaddah, 2016).

Masyarakat Desa Ganti Kecamatan Praya Timur Lombok Tengah, mengambil inisiatif untuk memanfaatkan sampah plastik sebagai salah satu usaha dalam membantu mengurangi permasalahan terkait sampah lingkungan. Dengan harapan produk yang dihasilkan adalah produk yang berkualitas dan akan diproduksi sebanyak-banyaknya dalam meningkatkan ekonomi masyarakat.

Berdasarakan analisis situasi di atas tujuan dari kegiatan pengabdian ini adalah untuk melatih masyarakat desa ganti dalam pengolahan sampah plastik menjadi barang bernilai guna dan ekonimis. Dengan adanya kegitan ini diharapkan akan berdampak pada peningkatan kesadaran masyarakat dalam pengelolaan sampah platik, sehingga dapat mengurangi dampak pencemaran lingkungan.

\section{METODE PELAKSANAAN}

Rancangan kegiatan yang dilakukan yaitu kegiatan pelatihan mengolah dan memanfaatkan sampah plastik menjadi barang bernilai ekonomis. Kegiatan ini dilaksanakan pada hari Selasa 5 Januari 2019 di Aula Kantor Desa Ganti. Kegiatan ini melibatkan ibu-ibu rumah tangga sebagai peserta pelatihan. Alat dipersiapkan seperti gunting, lilin, ember, korek, benang dan jarum jahit serta sabun. Sedangkan bahan yang dibutuhkan yaitu sampah plastik, kantong plastik transparan (bekas bungkus gula atau yang baru), sarung bantal yang terbuat dari kain dan pengharum lainnya. Adapun kegiatannya dibagi dalam 3 (tiga) tahapan yaitu (a) penjelasan materi umum tentang pemanfatan sampah; (b) tahapan persiapan dan pengumpulan; (c) tahapan pembuatan barang-barang bernilai ekonomis dari sampah plastik. Hasil pembuatan tersebut bisa digunakan sendiri dalam rumahnya dan bisa juga dijual di pasar jika pembuatannya lebih banyak.

\section{HASIL DAN PEMBAHASAN}

\section{Tahapan penjelasan umum materi tentang pemanfatan sampah}

Kegiatan ini dikemas dalam bentuk presentasi dan penjelasan dimana penyaji akan memberikan materi dalam bentuk ceramah dan tanya jawab dengan durasi waktu yang tidak lama. Dalam kegiatan ini semua materi yang berhubungan dengan tema pelatihan yang dipersiapkan dalam bentuk slide persentasi dengan tujuan memudahkan ibu-ibu menyaksikan langsung materi yang disampaikan. Pada kegiatan ini diberikan materi tentang pemanfatan sampah, perbedaan sampah organik dan anorganik, dampak negatif dan positif, serta potensi sampah jika diolah. Tidak hanya itu, masyarakat juga diinformasikan tentang bahaya penimbunan dan pembakaran sampah plastik serta dampak-dampaknya bagi lingkungan.

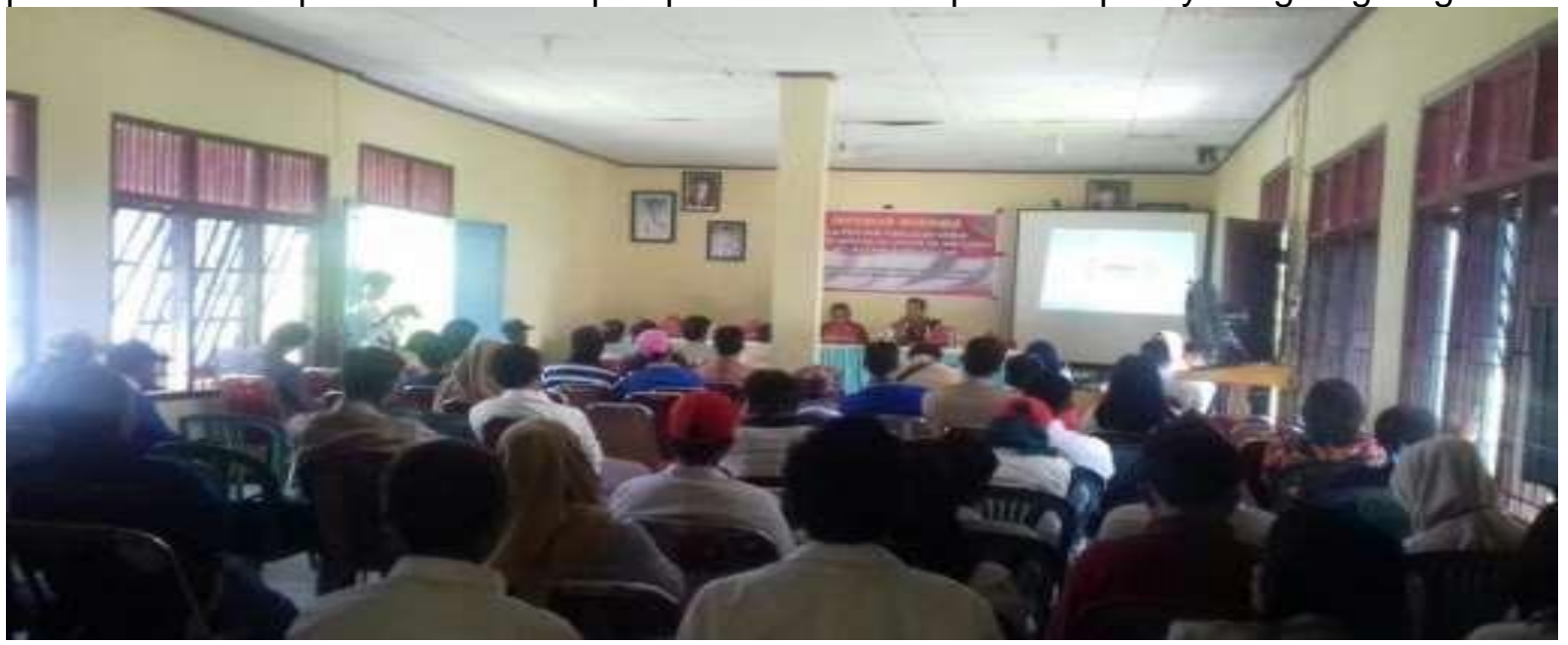

Gambar 1. Aktivitas penyampaian materi

\section{Tahapan persiapan dan pengumpulan}

Pengumpulan bahan-bahan berupa sampah plastik dilakukan sendiri oleh mitra dengan cara mengumpulkan dari rumah tangga dan warung sekitar. adapun langkah-langkah yang 
dilakukan adalah. 1) Mengumpulkan dan memilih sampah plastik sebanyak-banyaknya terutama sampah plastik yang tipis, seperti bekas bungkus makanan ringan, bekas bungkus permen, bungkus mie dan lain-lain. Pemilahan dan penyortiran ini bertujuan agar proses pengolahan menjadi barang-barang bernilai guna mudah dilakukan, 2) Membersihkan sampah plastik yang telah terkumpul tersebut dengan cara mencucinya dengan menggunakan sabun sampai bersih, \& 3) Mengeringkan sampah plastik yang telah dicuci tersebut sampai benar-benar kering dan tidak ada lagi yang kotor.

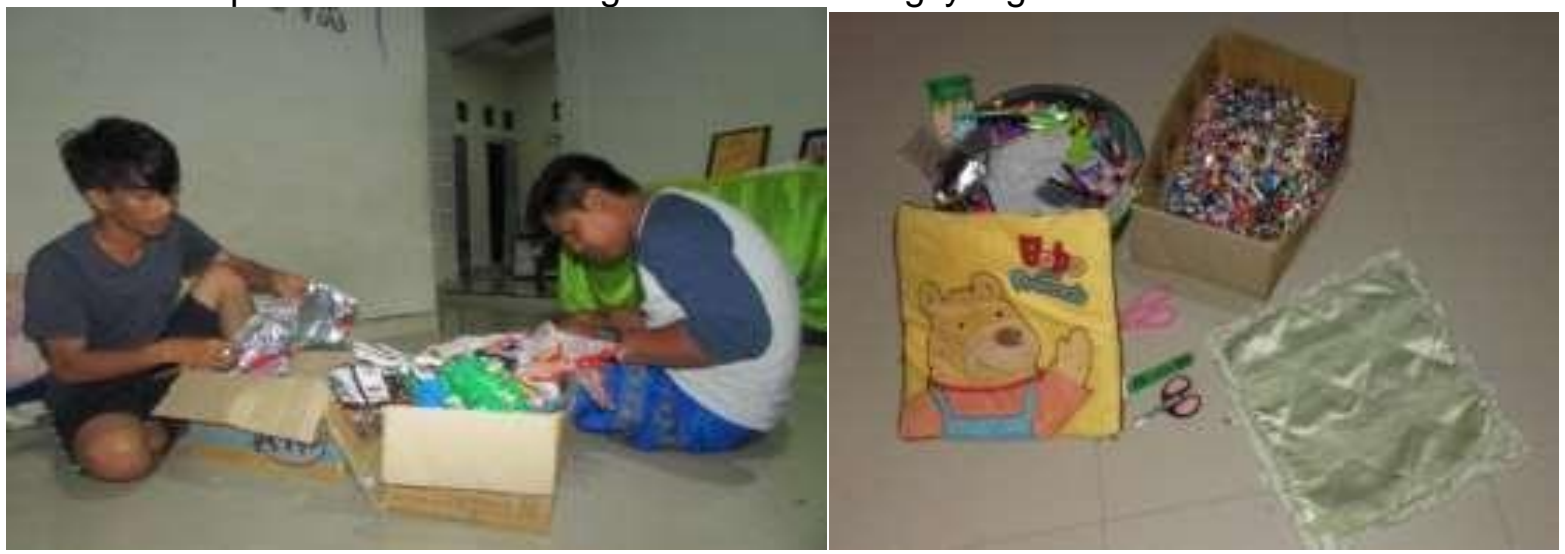

Gambar 2. Memilih sampah yang baik dan bagus digunakan

\section{Tahapan pembuatan barang dari sampah plastik}

Proses pembutan produk yang bernilai guna dan ekonomis dilakukan oleh mitra setelah pemberian materi tutorial oleh tim pengabdian. Kegitan berlangsung dengan baik. Adapaun tahapan-tahapan dalam pembutan sebagai berikut;

a. Setelah sampah kering, sampah plastik tersebut dipotong menjadi sampah yang kecilkecil dengan ukuran lebih kurang $1 \mathrm{~cm}$ sampai $3 \mathrm{~cm}$.

b. Memasukkan potongan-potongan sampah plastik tersebut kedalam kantong plastik yang telah disiapkan.

c. Memasukkan pewangi ke dalam kantong plastik tersebut secukupnya agar bantal menjadi harum.

d. Melipat ujung kantong plastik dan bakar perlahan-perlahan dengan api lilin untuk mengelem agar kantong plastik tertutup dengan rapat.

e. Menjahit resleting di salah satu sisi sarung bantal dan pemasangan hiasan yang indah pada sarung bantal dengan bantuan benang dan jarum jahit secara manual.

f. Kantong plastik yang telah terisi dengan potongan-potongan sampah plastik tersebut dimasukkan ke dalam sarung bantal yang telah disiapkan dan menjahit kembali sarung bantal setelah diisi kain.

g. Bantal unik sudah jadi dan siap digunakan. Hasil pembuatan tersebut bisa digunakan sendiri dalam rumahnya dan bisa juga dijual di pasar jika pembuatannya lebih banyak.
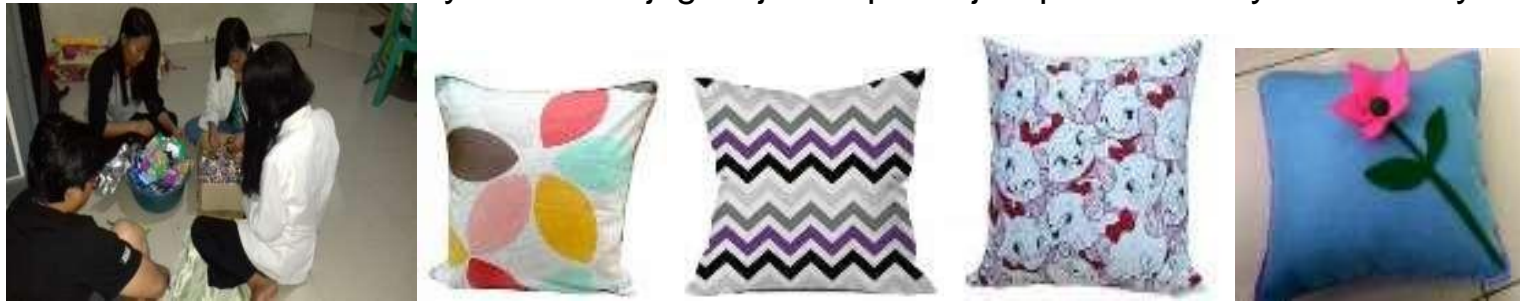

Gambar 3. Proses Pembuatan barang bernilai ekonomis, dan Produk yang sudah jadl

Sarung bantal berbahan sampah plastik memiliki beberapa kelebihan daripada bantal dari bahan lainnya. Kelebihannya adalah bisa digunakan dalam waktu yang lebih lama, mudah dicuci, cepat kering dan bisa bertahan dari jamur. Bila dilihat dari segi ekonomis harga sampah lebih murah dan lebih mudah didapatkan dalam kehidupan sehari-hari. Pembuatan batal dari sampah plastik pada prinsipnya bertujuan untuk menanggulangi permasalahan banyaknya limbah plastik yang berada di Desa Tolada. Setelah dilakukan perhitungan biaya yang dikeluarkan dalam pembuatan dan biaya yang berkaitan dengannya, maka bisa 
diestimasi harga jual yang bisa dipasarkan pada masyarakat antara $\mathrm{Rp} 10.000$ sampai $\mathrm{Rp}$ 25.000 tergantung bentuk dan motif (style) yang ada pada bantal tersebut.

Kegitan pelatihan berjalan dengan baik sesuai dengan perencanaan yang telah dibuat oleh tim pengabdian dan mitra. Dampak dari kegiatan yang dilakukan antara lain 1) adanya peningkatan pengetahuan mitra dalam pengolahan sampah plastik menjadi produk yang memeiliki nilai guna dan ekonimis, 2) terbentuknya keterampilan mitra dalam pengolahan sampah plastik menjadi beberapa produk, seperti sarung bantal, bunga dan beberapa barang yang bernilai ekonomis, dan 3) terbentuknya kesadaran mitra bahwa sampah platik merupakan masalah yang harus diatasai baik dengan cara meminimalisir penggunaan dan pengolahan.

\section{KESIMPULAN}

Sampah plastik dapat diatasi jika setiap pengguna memiliki kesadaran dan bijak dalam memanfatakan platik. Kegiatan pengabdian yang dilakukan telah memberikan dampak yang cukup baik bagi mitra antara lain terbentuknya pemahaman dan keterampilan tentang pengolahan sampah platik menjadi barang bernilai guna. Selain itu kesadaran masyarakat akan penggunaan plastik secara bijak meningkat.

\section{REKOMENDASI}

Berdasarkan temuan-temuan selama kegiatan pengabdian, tim pengabdian merekomendasikan bahwa masyarakat perlu ada pembinaan dan pendampingan tentang pengolahan sampah anorganik amupun organik secara berkelanjutan, sehingga masyarakat benar-benar dapat secara mandiri dalam pengolahan sampah.

\section{DAFTAR PUSTAKA}

Baqiroh, Nur Faizah A B (2019). Timbunan Sampah Nasional Capai 64 Juta Ton Per Tahun, [online], dari: https://ekonomi.bisnis.com/read/20190221/99/891611/timbulan-sampahnasional-capai-64-juta-ton-per-tahun [10 Desember 2019]

Buntojo P.S.I, (2019). Meningkatnya Tren Kesadaran Lingkungan Dengan Mengurangi Penggunaan Plastik, [online], dari:www.brandwatc.com/blog/reactplastic-data/ [2 Desember 2019]

Sucipto, C D. 2012. Teknologi Pengolahan Daur Ulang Sampah. Yogyakarta: Gosyen Publishing.

Dani, M. H (2018). Sampah dan Problematika Masyarakat Perkotaan, [online], dari: https://analisadaily.com/berita/arsip/2018/3/18/523178/sampah-danproblematikamasyarakat-perkotaan/ [25 Desember 2019]

Dwiyatmo, K. 2017. Pencemaran Lingkungan dan Penanganannya. Yogyakarta: PT. Citra Aji Parama.

Handoyo, (2019). Sampah Plastik Menunjukkan Tren Peningkatan Dalam 10 Tahun Terakhir, [online], dari: www.amp.kontan.co.id/news/sampahplastik-menunjukkan-tren-peningkatandalam-10-tahun-terakhir [2 Desember 2019]

Mawaddah N.N, (2016). Strategi Adaptasi Pemulung tehadap Dampak yang Dtimbulakn Tempat Pembuangan Akhir Sampah Tamangapa Kecamatan Manggala Kota Makassar. Skripsi. Universitas Negeri Makassar. http://eprints.unm.ac.id/4707/

Nugroho, Panji. 2013. Panduan Membuat Kompos Cair. Jakarta: Pustaka baru Press.

Rizal, M. 2011. Analisis Pengelolaan Persampahan Perkotaan (Studi kasus pada kelurahan Boya Kecamatan Banawa Kabupaten Danggola). Jurnal SMART ek, 9 (2) : 155-172

Yusuf, S. 2015. Pola Kerja Pemulung dan Relasinya terhadap Kehidupan Sosial serta Kesejahteraan Pemulng di TPA Bukit Pinang Samarinda.ejournal Sosiatri-Sosiologi, Volume 3, Nomor 4, 2015: 121-136.

Wicaksono A.M., \& Arijanto (2017) Pengolahan Sampah Plastik Jenis PET (Polyethilene Perepthalathe) Menggunakan Metode Pirolisis Menjadi Bahan Bakar Alternatif. Jurnal $\begin{array}{llrr}\text { Teknik } & \text { Mesin } & \text { S-1 } & \text { 5(1). }\end{array}$ https://ejournal3.undip.ac.id/index.php/itm/article/view/16921/16219.

Undang-Undang Republik Indonesia Nomor 18 Tahun 2008 Tentang Pengelolaan Sampah. https://pelayanan.jakarta.go.id/download/regulasi/undang-undang-nomor-18-tahun2008-tentang-pengelolaan-sampah.pdf 